\title{
EVALUASI SELEKTIVITAS JARING INSANG DI TELUK KOTANIA, SERAM BAGIAN BARAT
}

\author{
Grace Hutubessy \\ Jurusan Pemanfaatan Sumberdaya Perikanan, Fakultas Perikanan dan \\ IImu Kelautan, Universitas Pattimura, Ambon, Maluku, Indonesia \\ E-mail : grace.hutubessy@yahoo.com
}

Received February 2020, Accepted April 2020

\begin{abstract}
ABSTRAK
Jaring insang digolongkan sebagai alat tangkap yang ramah lingkungan mengingat ukuran ikan yang tertangkap dipengaruhi oleh ukuran mata jaring yang digunakan. Penelitian yang dilakukan selama 2013-2014 di perairan Kotania, Kabupaten Seram Bagian Barat bertujuan untuk menghitung kelimpahan ikan pada spektrum ukuran (abundance sizespectrum) berdasarkan habitat ikan pada waktu yang berbeda. Data dikumpulkan melalui logbook yang diisi oleh nelayan Dusun Pulau Osi dan Dusun Wael dengan daerah penangkapan di Teluk Kotania. Distribusi panjang ikan hasil tangkapan setiap mata jaring menunjukkan kisaran panjang yang tidak beraturan yang bisa menimbulkan selektivitas yang tidak konsisten. Ketidakpastian selektivitas jaring insang yang dioperasikan pada perairan dangkal disebabkan oleh perubahan pilihan habitat sebagai daerah penangkapan nelayan. Spektrum panjang menunjukkan distribusi panjang yang unimodal dengan jumlah ikan jenis ikan berukuran kecil tinggi dan menurun secara eksponensial untuk jenis ikan berukuran besar. Mengingat ikan besar mempunyai peranan penting dalam komunitas, dan kurang rentan terhadap jaring insang, kami menyimpulkan bahwa jaring insang adalah alat yang ramah lingkungan.
\end{abstract}

Kata Kunci : Jaring Ingsang; Kelimpahan, Spektrum Ukuran; Multispesies; Perubahan Spatial; Perubahan Temporal

\section{ABSTRACT}

EVALUATION OF GILLNET SELECTIVITY IN KOTANIA BAY, WEST PART OF SERAM. Gillnets are categorized as environmentally friendly fishing gear convinced by its selectivity. Study conducted at Kotania Bay, West Seram Regency, for two years (2012-2013) aimed to count the abundance size-spectrum on habitat for evaluating the catch of gillnets. Length distribution of catch for each mesh size showed irregular ranges, which may lead to selectivity uncertainties. Data was collected from logbooks filled by fishers from Osi Island and Wael. Uncertainty of gillnets selectivity which were operated in shallow waters was influenced by the fishers' habitat preference that was distinct temporally. The size-spectra of 
exhibited unimodal length distribution with high catch of small-bodied species and lowered exponentially towards large-bodied species. As largebodied species play important role in the community and they are less vulnerable to gillnets, we concluded that the practices of gillnet at Kotania Bay are environmentally friendly gear.

Keywords : Gillnets; Abundance, Size Spectrum; Multi-Species; Spatial Change; Temporal Change

\section{PENDAHULUAN}

Mantan Menteri Kelautan dan Perikanan Indonesia, Ibu Susi Pudjiastuti, menyatakan bahwa jaring insang merupakan alat tangkap yang ramah lingkungan (Purbaya, 2017). Pernyataan ini benar secara umum mengingat ukuran ikan yang tertangkap tergantung pada ukuran mata jaring yang digunakan, makin besar mata jaring maka makin besar ikan yang tertangkap. Penggunakan jaring dengan mata besar akan menangkap ikan yang sudah layak tangkap sehingga recruitment overfishing dapat dihindari (Froese, 2004). Sebagai penunjuang pernyataan ini, penelitan selektivitas jaring insang sudah sering dilakukan (contohnya Allison et al. 2009; Hutubessy and Syahailatua, 2010; Hutubessy, 2011). Hasil-hasil penelitian selektivitas jaring insang di atas mempunyai peranan penting dalam upaya perlindungan populasi singlespecies (species tunggal).

Nelayan di sekitar Teluk Kotania menggunakan jaring untuk menangkap ikan karang. Dengan menggunakan berbagai ukuran mata jaring, keragaman jenis hasil tangkapan cukup tinggi dengan ukuran yang bervariasi. Aktivitas penangkapan bersifat komersil (untuk dijual) dan nelayan menargetkan untuk menangkap ikan kerapu karena harga jualnya yang tinggi.

Penelitian ini mengevaluasi tingkat selektivitas alat tangkap jaring insang dengan pendekatan multispecies. Tujuan dari penelitian ini adalah menghitung kelimpahan ikan pada spektrum ukuran (abundance sizespectrum) berdasarkan habitat ikan pada waktu yang berbeda. Dengan pendekatan berbasis ukuran, dampak penangkapan dengan jaring insang terhadap komunitas ikan demersal dapat dievaluasi melalui perubahan spasio-temporal spektrum ukuran.

\section{MATERI DAN METODE}

\section{Lokasi Penelitian dan Metode Sampling}

Teluk Kotania (Gambar 1) menjadi pilihan lokasi penelitian jaring insang selama 2 tahun (2013 dan 2014). Data hasil tangkapan jaring insang diperoleh melalui pengisisan logbook oleh nelayan yang berdomisili di sekitar Teluk Kotania. Data yang diisi oleh nelayan terdiri dari ukuran mata yang digunakan, waktu penangkapan (awal dan akhir), lokasi penangkapan beserta habitatnya. Nelayan dibekali dengan gambar 
ikan untuk mengidentifikasi jenis tangkapannya. Gambar ikan disadur dari (Allen, 1999). Setiap jenis ikan yang tertangkap diukur panjang cagaknya (cm). Setiap bulan, logbook dikumpulkan dari 8 nelayan yang berdomisili di dusun Pulau Osi dan Wael.

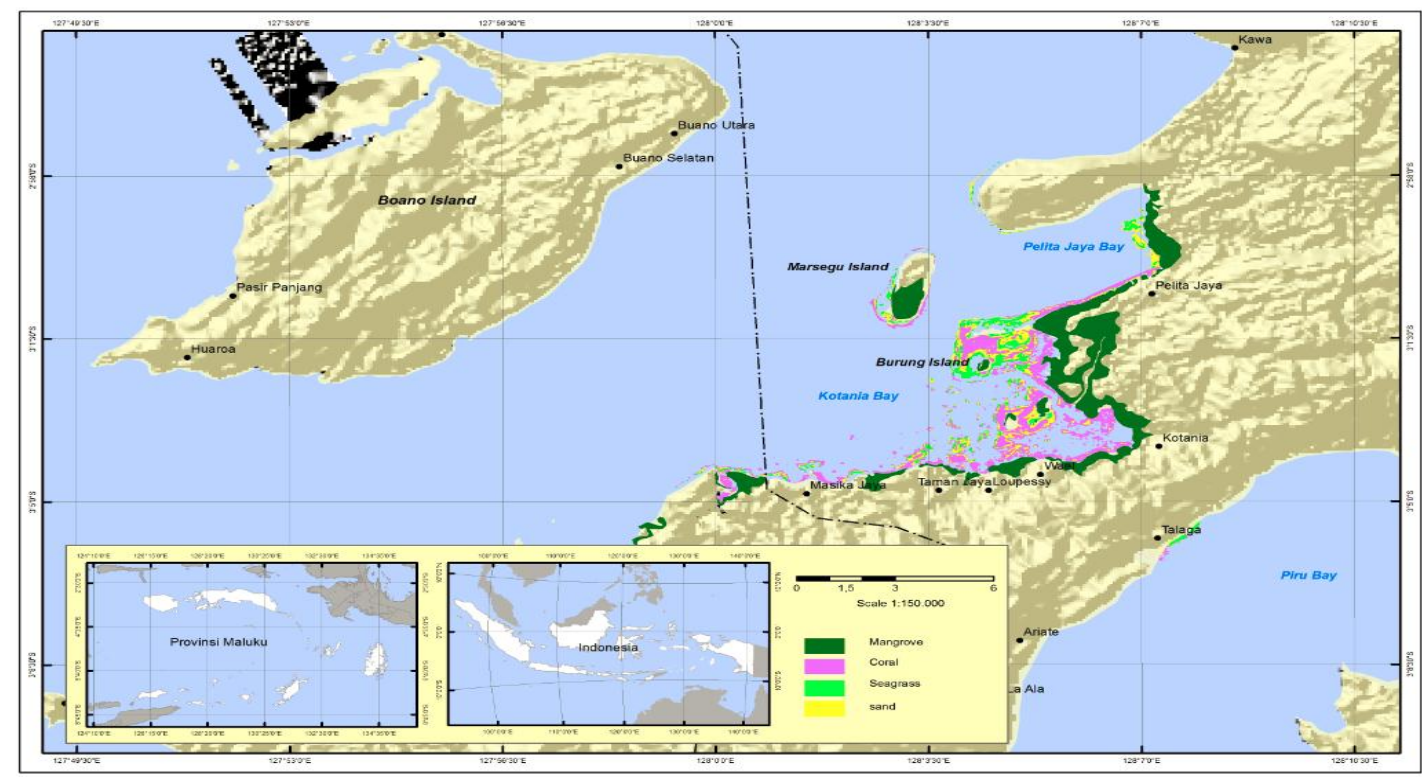

Gambar 1. Peta Teluk Kotania yang terletak di Kabupaten Seram Bagian Barat, Provinsi Maluku

\section{Spesifikasi Jaring Insang}

Nelayan menggunakan 5 ukuran mata jaring, 1.5”, 2", 2.25", 2.5" dan 4". Satu piece jaring dibagi menjadi 3 bagian karena untuk dioperasikan di perairan dangkal (Gambar 2). Tidak dilaporkan oleh nelayan jumlah piece jaring yang digunakan, maka diasumsikan nelayan menggunakan 3 piece jaring.

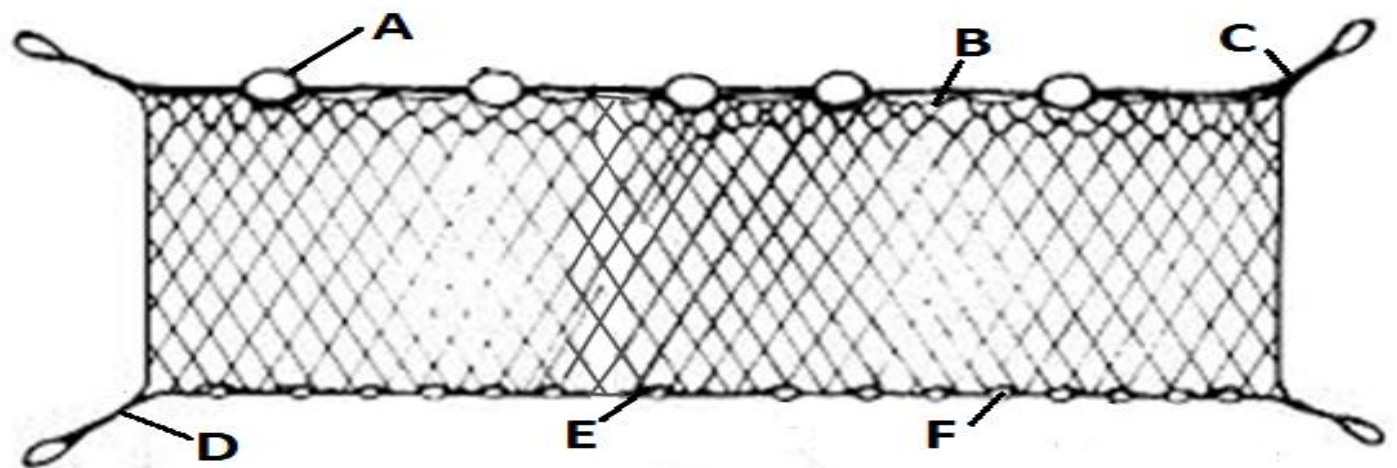

Gambar 2. Bagian jaring insang yang umum digunakan di Teluk Kotania : (A) pelampung; (B) Tali ris atas; (C) Tali pelampung; (D) Tali pemberat;

(E) Tali iris bawah; (F) Pemberat 


\section{Standarisasi CPUE}

Mengingat ukuran mata jaring yang digunakan berbeda dan durasi penangkapan bervariasi, standarisasi hasil tangkapan jaring insang perlu dilakukan. Persamaan yang dipakai untuk standarisasi merupakan turunan dari persamaan CPUE dalam kondisi ekuilibrium (King, 2007): CPUE = b.f, menjadi :

Mata jaring 1.5"

Mata jaring 2", 2,25" 2,5" dan 4" : CPUE $_{\text {standar }}=\mathrm{CPUE}_{\text {actual }}{ }^{*}(2 / \text { durasi })^{0.476}$

Untuk kedua kelompok ukuran mata jaring di atas, durasi penangkapan rata-rata $\left(f_{\text {rerata }}\right)$ adalah 2 jam dengan nilai slope $b$ yang berbeda (0.3685 dan 0.476 ), diperoleh dari hubungan regresi hasil tangkapan dan durasi penangkapan pada masing-masing jaring Spektrum ukuran (Size-spectrum)

Untuk menggambarkan perubahan hasil tangkapan secara temporal, size-spectrum sudah diperkenalkan sebagai suatu cara yang tepat untuk dapat membedakan perubahan komunitas ikan yang terjadi akibat penangkapan (Hall et al. 2006; Law et al. 2016; Edwards et al. 2017). Size-spectrum merupakan penggabungan frekuensi panjang ikan multi-jenis yang diaplikasikan untuk mengevaluasi komunitas ikan (Jung and Houde, 2005). Kami mencoba menggunakan size spectra untuk mempelajari spatio-temporal daerah penangkapan dan panjang maksimum jenis ikan yang tertangkap oleh jaring insang.

\section{HASIL DAN PEMBAHASAN}

\section{Selektivitas Jaring Insang}

Sebanyak 6084 individu ikan hasil tangkapan jaring insang yang mewakili 125 jenis tertangkap selama 507 trip penangkapan (Tabel 1).

Tabel 1. Ringkasan hasil tangkapan jaring insang menurut ukuran mata jaring yang berbeda.

\begin{tabular}{lllll}
\hline Mata jaring & $\begin{array}{l}\text { Jumlah } \\
\text { trip }\end{array}$ & $\begin{array}{l}\text { Jumlah } \\
\text { jenis }\end{array}$ & $\begin{array}{l}\text { Jumlah } \\
\text { ikan }\end{array}$ & $\begin{array}{l}\text { Panjang } \\
\text { rerata }(\mathrm{cm})\end{array}$ \\
\hline 1,5 & 31 & 21 & 216 & 31,3 \\
2 & 40 & 38 & 363 & 16,8 \\
2,25 & 185 & 90 & 3145 & 19,7 \\
2,5 & 40 & 37 & 461 & 15,3 \\
4 & 211 & 44 & 1899 & 18,5 \\
\hline Total & 507 & 125 & 6084 & \\
\hline
\end{tabular}

Hasil ini menunjukkan bahwa ukuran ikan yang tertangkap bervariasi menurut mata jaring yang digunakan. Panjang rata-rata terbesar 
justru tertangkap pada ukuran mata jaring yang terkecil (1,5"). Pada Gambar 3 terlihat bahwa distribusi panjang ikan yang tertangkap mengindikasikan adanya ketidakpastian (uncertainty) selektivitas jaring insang dibandingkan dengan kondisi yang seharusnya terjadi di mana makin besar ukuran mata jaring yang digunakan, makin besar ukuran ikan yang tertangkap (Martasuganda, 2008). Dari hasil ini, kami mencoba mengevaluasi faktor yang mempengaruhi ketidakpastian di atas, di antaranya perubahan habitat pada lokasi penangkapan jaring insang.

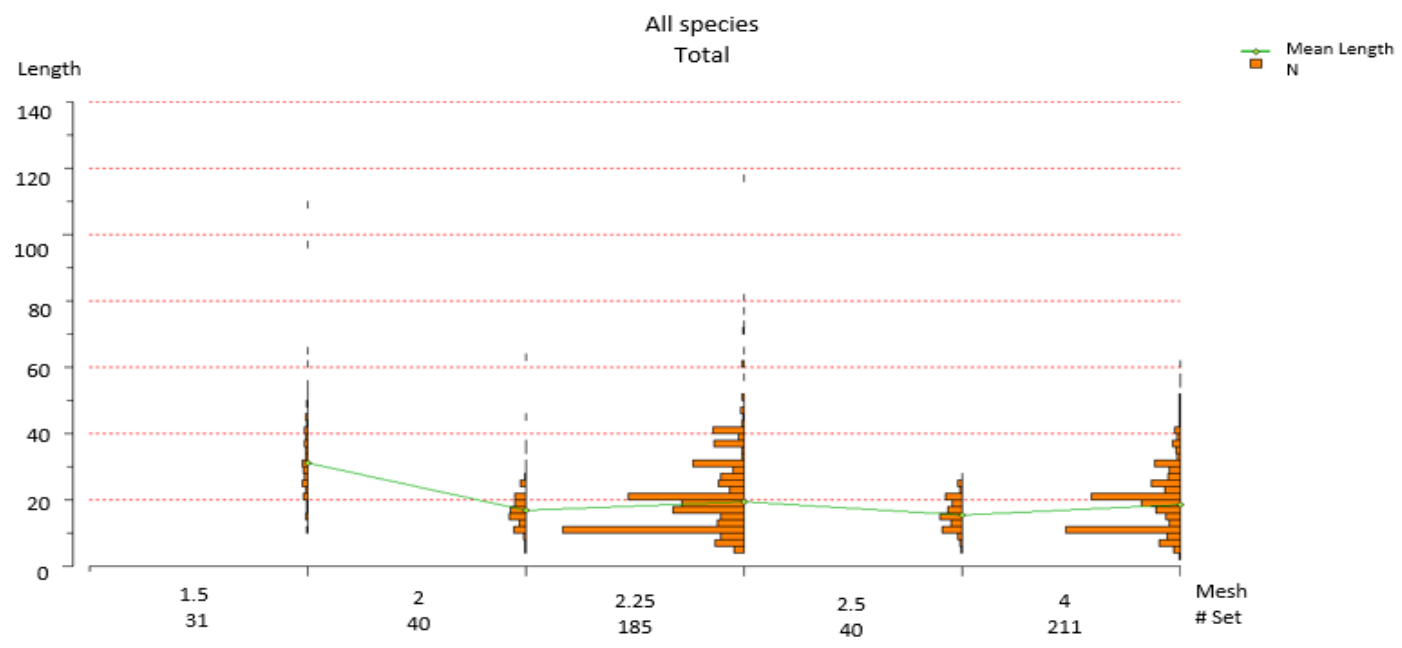

Gambar 3. Distribusi panjang ikan per-mata jaring

\section{Habitat Daerah Penangkapan}

Sebanyak 9 jenis habitat daerah penangkapan jaring insang diinformasikan oleh nelayan (Tabel 2), terdiri dari karang, pasir, lumpur dan lamun, juga percampuran antara karang dan pasir, karang dan lamun, karang dan lumpur, pasir dan lamun, pasir dan lumpur. Lumpur merupakan habitat yang terbanyak dipilih nelayan untuk meletakkan jaring insang mereka (173 trip) dan menghasilkan jumlah tangkapan tertinggi (2164 individu). Panjang rata-rata ikan terbesar $(22,0 \mathrm{~cm})$ tertangkap pada habitat campuran karang dan pasir, diikuti oleh lamun $(21,4 \mathrm{~cm})$ dan karang $(21,1 \mathrm{~cm})$,

Tabel 2. Ringkasan hasil tangkapan jaring insang pada habitat yang berbeda

\begin{tabular}{lllll}
\hline Habitat & $\begin{array}{l}\text { Jumlah } \\
\text { trip }\end{array}$ & $\begin{array}{l}\text { Jumlah } \\
\text { jenis }\end{array}$ & $\begin{array}{l}\text { Jumlah } \\
\text { ikan }\end{array}$ & $\begin{array}{l}\text { Panjang } \\
\text { rerata }(\mathrm{cm})\end{array}$ \\
\hline Karang & 12 & 15 & 106 & 21,1 \\
Karang \& lumpur & 9 & 18 & 166 & 15,8 \\
Karang \& pasir & 90 & 87 & 1130 & 22,0 \\
Karang \& lamun & 25 & 44 & 378 & 17,7 \\
Lumpur & 173 & 24 & 2164 & 15,9 \\
Pasir & 21 & 27 & 157 & 19,9
\end{tabular}




\begin{tabular}{lllll}
\hline Habitat & $\begin{array}{l}\text { Jumlah } \\
\text { trip }\end{array}$ & $\begin{array}{l}\text { Jumlah } \\
\text { jenis }\end{array}$ & $\begin{array}{l}\text { Jumlah } \\
\text { ikan }\end{array}$ & $\begin{array}{l}\text { Panjang } \\
\text { rerata }(\mathrm{cm})\end{array}$ \\
\hline Pasir \& lumpur & 2 & 5 & 79 & 16,0 \\
Pasir \& lamun & 33 & 51 & 637 & 20,3 \\
Lamun & 53 & 45 & 735 & 21,4 \\
\hline
\end{tabular}

Hasil tangkapan jaring insang pada periode yang berbeda membentuk size-spectra dengan modus tunggal. Modus panjang ikan berkisar antara $10-15 \mathrm{~cm}$, dan jenis ikan yang berukuran besar (large body species) hanya sedikit yang tertangkap (Gambar 4).
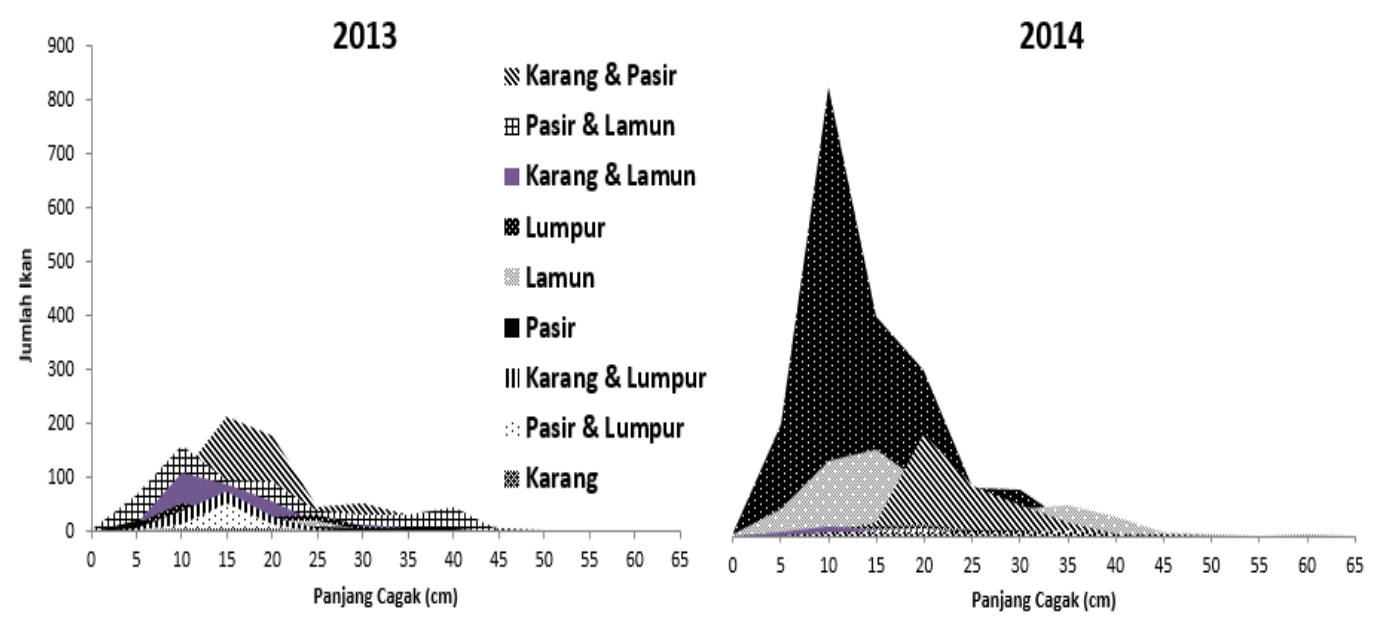

Gambar 4. Spatio-temporal spektrum ukuran multi-species ikan hasil tangkapan jaring insang

Distribusi panjang ikan secara spatio-temporal menunjukkan perubahan pilihan habitat daerah penangkapan oleh nelayan jaring insang (Gambar 4). Pada tahun 2013, 9 habitat menjadi pilihan nelayan sebagai daerah penangkapan jaring insang. Pada habitat campuran pasir dan lamun serta karang dan lamun, ikan berukuran $10 \mathrm{~cm}$ lebih banyak tertangkap. Pada habitat campuran karang dan pasir lebih banyak ikan berukuran $10-20 \mathrm{~cm}$ yang tertangkap. Walaupun dalam jumlah yang tidak banyak, hasil tangkapan pada habitat lumpur bervariasi dari $6-39 \mathrm{~cm}$. Ukuran terbesar $(60 \mathrm{~cm})$ tertangkap pada habitat karang \& pasir, karang dan lamun, pasir serta pasir \& lamun. Terjadi perubahan yang signifikan pada tahun 2014 di mana habitat lumpur menjadi pilihan nelayan dari 8 habitat yang dilaporkan. Ukuran ikan yang tertangkap berkisar antara 5$55 \mathrm{~cm}$, didominasi oleh ukuran $10 \mathrm{~cm}$. Habitat lamun juga menjadi pilihan nelayan pada tahun ini. Hasil tangkapan di lamun mempunyai ukuran yang berkisar antara $5-60 \mathrm{~cm}$, didominasi ikan berukuran $15-20 \mathrm{~cm}$. Hasil tangkapan pada habitat campuran karang dan pasir didominasi oleh ikan berukuran lebih besar $(25 \mathrm{~cm})$ dibandingkan tahun sebelumnya $(20 \mathrm{~cm})$. Perubahan habitat daerah penangkapan gillnet memicu terjadinya perubahan dari ukuran ikan yang tertangkap. 
Habitat daerah penangkapan yang berperan penting dalam ekosistem kurang mendapat perhatian atau diabaikan dalam penelitian selektivitas alat tangkap (Waterhouse et al. 2014). Pada selektivitas populasi, penangkapan secara spasial mempengaruhi mortalitas penangkapan $(f)$ relatif terhadap umur atau ukuran yang ada di dalam populasi tersebut. Sampson and Scott (2011) menemukan perubahan spasial distribusi dari mortalitas penangkapan dan pergerakan atau perpindahan ikan antar lokasi merupakan faktor yang mempengaruhi bentuk kurva selektivitas populasi. Fungsi habitat sebagai daerah pembesaran, daerah mencari makan, daerah perlindungan atau daerah ruaya, akan berpengaruh terhadap ukuran ikan yang ada di dalam habitat tersebut. Berdasarkan pengalaman, nelayan mengetahui daerah penangkapan jenis target tertentu. Konsekuensinya, habitat yang menjadi preferensi nelayan untuk beroperasi akan berubah-ubah sesuai tujuan target penangkapan.

Ukuran ikan mempunyai relasi dengan riwayat hidup ikan seperti fekunditas, pertumbuhan somatik, umur matang gonad dan umur maksimum, di mana jenis ikan berukuran besar cenderung mempunyai fekunditas tinggi, pertumbuhan yang lambat, kematangan gonad yang terlambat serta umur maksimum yang lebih besar dari pada jenis ikan dengan ukuran kecil (Reynolds et al. 2001; Hutchings, 2002). Juga dikatakan, ikan berukuran besar memiliki resiko lebih rentan terhadap eksploitasi daripada ikan yang berukuran lebih kecil, dan kapasitas untuk menggantikan jumlah ikan yang telah dieksploitasi sangat lemah (Reynolds et al. 2001). Selama perbedaan mortalitas penangkapan dapat dikontrol melalui penangkapan yang selektif, jumlah ikan berukuran besar akan berkurang lebih cepat dibandingkan ikan berukuran lebih kecil (Jennings et al. 1998; Froese et al. 2016). Pada hasil penelitian ini, jaring insang dengan 5 mata jaring yang berbeda menunjukkan penurunan hasil tangkapan secara eksponensial terhadap ikan berukuran besar. Walaupun terjadi perubahan habitat daerah penangkapan, jaring insang tetap menunjukkan penurunan hasil tangkapan terhadap ikan besar,

\section{KESIMPULAN}

Praktek jaring insang di Teluk Kotania menggambarkan ketidakpastian selektivitas jaring. Spectrum kelimpahan secara spatial menggambarkan perubahan kelimpahan ikan terjadi pada habitat yang berbeda. Secara temporal, spektrum kelimpahan berdasarkan ukuran ikan yang tertangkap juga menunjukkan perubahan. Ikan yang tertangkap berukuran lebih besar tetapi kelimpahannya menurun. Perubahan pilihan habitat oleh nelayan memicu terjadinya inkonsistensi selektivitas jaring insang. Jaring insang yang dipraktekkan di Teluk Kotania memiliki keramahan terhadap komunitas ikan karang karena peluang tertangkapnya jenis ikan berukuran besar relatif kecil. Jika jenis ikan berukuran besar banyak tertangkap, populasi ikan tersebut dapat terancam. Habitat pilihan sebagai daerah penangkapan yang berubahubah akan mempengaruhi ketidakpastian selektivitas jaring insang. 
Walaupun terlihat adanya ketidakpastian selektivitas jaring insang berdasarkan ukuran mata jaring, alat tangkap ini memberikan peluang kecil tertangkapnya ikan berukuran besar sehingga komunitas ikan demersal tetap terjaga.

\section{UCAPAN TERIMA KASIH}

Terlaksananya penelitian ini didukung oleh dana penelitian hibah kompetitif nasional MP3EI selama tahun 2012-2014. Kepada nelayan di Pulau Osi dan Dusun Wael, Kabupaten Seram Bagian Barat, terima kasih yang tak terhingga kami haturkan atas kesabaran dan kesetiaan menyediakan data demi kelancaran penelitian ini.

\section{DAFTAR PUSTAKA}

Allen G, R. Swainston, and J. Ruse. 1999. Marine Fishes of South-EastAsia, A field Guide for Anglers and Divers. Australia: Western Australia Museum.

Allison M.E., I.F. Vincent-Akpu, A.D.I. George. 2009. Gillnet Selectivity and Abundance in The Palailia pellucida (Boulenger, 1901) (Schilbaidae) Fishery of The Freshwater Reaches of The Lower Nun River, Niger Delta, Nigeria. Journal of Fisheries International. 4(1): 5-7.

Babcock, E. A., R. Coleman, M. Karnauskas, and J. Gibson. 2013. "Length-Based Indicators of Fishery and Ecosystem Status: Glover's Reef Marine Reserve, Belize." Fisheries Research 147: 434-45.

Clement, T. A., K. Pangle, D. G. Uzarski, and B. A. Murry. 2014. "Effectiveness of Fishing Gears to Assess Fish Assemblage Size Structure in Small Lake Ecosystems." Fisheries Management and Ecology 21 (3): 211-19.

Edwards, A.M., J.P.W. Robinson, M. J. Plank, Julia K. Baum, and J. L. Blanchard. 2017. "Testing and Recommending Methods for Fitting Size Spectra to Data." Methods in Ecology and Evolution 8 (1): 5767.

Froese, R., H. W., D. Gascuel, U. R. Sumaila, and D. Pauly. 2016. "Minimizing the Impact of Fishing." Fish and Fisheries 17 (3): 785802.

Hinton, MG, and M N Maunder. 2003. "Methods for Standardizing CPUE and How to Select among Them." 
Law, R., M. J. Plank, and J. Kolding. 2016. "Balanced Exploitation and Coexistence of Interacting, Size-Structured, Fish Species." Fish and Fisheries 17 (2): 281-302. .

Winker, H., S. E. Kerwath, and C. G. Attwood. 2014. "Proof of Concept for a Novel Procedure to Standardize Multispecies Catch and Effort Data." Fisheries Research 155: 149-59.

Clement TA, K. Pangle, D.G. Uzarski, B.A. Murry. 2014. Effectiveness Of Fishing Gears To Assess Fish Assemblage Size Structure In Small Lake Ecosystems. Fisheries Management and Ecology. 21(3), 211219.

Edwards A.M., J.P.W. Robinson, M.J. Plank, J.K. Baum, J.L. Blanchard. 2017. Testing And Recommending Methods For Fitting Size Spectra To Data. Methods in Ecology and Evolution. 8(1): 57-67.

Froese R. 2004. Keep It Simple: Three Indicators to Deal with Overfishing. Fish and Fisheries. 5: 86-91.

Froese R, H. Winker, D. Gascuel, U.R. Sumaila, D. Pauly. 2016. Minimizing the Impact of Fishing. Fish and Fisheries. 17(3): 785802.

Hall S.J., J.S. Collie, D.E. Duplisea, S. Jennings, M. Bravington, J. Link. 2006. A Length-Based Multispecies Model for Evaluating Community Responses to Fishing. Canadian Journal of Fisheries and Aquatic Science. 63(6): 1344-1359.

Hinton M.G., and M.N. Maunder. 2004. Methods for standardizing CPUE and how to select among them. Working Paper. Inter-American Tropical Tuna Commission.

Hutchings J.A. 2002. Life histories, In Handbook of Fish and Fisheries. Edited by PJB. Hart and JD. Reynolds. Oxford: Blackwell Science Ltd.

Hutubessy B.G. and A. Syahailatua. 2010. Performance of Gillnet-Size Selectivity for Three Flying Fish Species in Ambon Waters, Maluku Province. Marine Research in Indonesia. 35(2): 39-46.

Hutubessy G. 2011. Encircling Gillnet Selectivity for Oxeye Scad (Selar boops, CUVIER 1933) in the coast of Waai, Ambon Island. Journal of Coastal Development. 14(2): 125-130.

Jennings S, J.D. Reynolds, and S.C. Mills. 1998. Life History Correlates of Responses to Fisheries Exploitation, Proceedings of the Royal Society of London B: Biological Sciences. 265: 333-339. 
King, M. 2007. Fisheries Biology, Assesment and Management. Second edition. Blackwell Publishing Ltd, Oxford, UK.

Jung S. and E.D. Houde. 2005. Fish Biomass Size Spectra in Chesapeake Bay. Estuary. 28 (2): 226-240.

Law R., M.J. Plank, and J. Kolding. 2016. Balanced Exploitation And Coexistence Of Interacting, Size-Structured, Fish Species. Fish and Fisheries. 17(2): 281-302.

Purbaya A.A. 2017. Menteri Susi Ganti Alat Cantrang Dengan Alat Ramah Lingkungan, Kompas 20 September 2017.

Reynolds J.D., S. Jennings, N.K. Dulvy. 2001. Life Histories of Fishes and Population Responses to Exploitation. In Conservation of Exploited Species. Edited by J.D. Reynolds, G.M. Mace, K.H. Redford, and J.G. Robinson, Cambridge: Cambridge University Press.

Sampson D.B., and R.D. Scott. 2011. A Spatial Model for Fisheries AgeSelection at The Population Level. Canadian Journal of Fisheries and Aquatic Science. 68: 1077-1086.

Martasuganda, S. 2008. Jaring Insang - Gillnet. Bogor: Departemen Pemanfaatan Sumberdaya Perikanan IPB.

Waterhouse L., D.B. Sampson, M. Maunder, B.X. Semmens. 2014. Using Areas-As-Fleet Selectivity to Model Spatial Fishing: Asymptotic Curves Are Unlikely Under Equilibrium Conditions. Fisheries Research. 158: 15-25. 